\title{
Laboratory assessment of thermal characteristics of three phacoemulsification tip designs operated using torsional ultrasound
}

This article was published in the following Dove Press journal:

Clinical Ophthalmology

13 June 2016

Number of times this article has been viewed

\author{
Jaime Zacharias \\ Phacodynamics Laboratory, Pasteur \\ Ophthalmic Clinic, Santiago, Chile
}

Correspondence: Jaime Zacharias Phacodynamics Laboratory, Clinica Oftalmologica Pasteur, Av Luis Pasteur 5917, Santiago 6670775, Chile Tel +56 25205900

Fax +5625205999

Email jaime.zacharias@gmail.com
Purpose: Ultrasound activation of phacoemulsification (phaco) tips can create considerable thermal energy that may increase the risk of tissue damage during cataract surgery. The purpose of this study was to define the thermal profiles of three phaco tip designs in simulated surgical conditions.

Methods: In this laboratory investigation, sleeved phaco tips (mini-flared Kelman ${ }^{\circledR}$ tip with aspiration bypass port and Intrepid ${ }^{\circledR}$ Balanced Tip with aspiration bypass port, and MST A1 bent-mini phaco tip (without aspiration bypass) were tested using an ultrasonic phaco device operated in torsional mode at power levels of $50 \%, 75 \%$, and $100 \%$ amplitude. An automated fixture applied a $30 \mathrm{~g}$ load to simulate compression against the incision site, leading to friction between the silicone sleeve and the titanium tip. Temperature was recorded by high rate infrared imaging under conditions of free flow and occlusion, which was simulated by clamping the aspiration line. Data were summarized using descriptive statistics.

Results: Baseline temperatures of $\sim 26^{\circ} \mathrm{C}$ were observed for all tips. During ultrasonic operation at $50 \%, 75 \%$, and $100 \%$ amplitude, temperatures were lower for the mini-flared and balanced tips versus the bent-mini tip, both when load was applied and during occlusion. The bent-mini tip reached temperatures as high as $70^{\circ} \mathrm{C}$ during occlusion with load when operated at $100 \%$ amplitude, whereas the mini-flared tip remained $<50^{\circ} \mathrm{C}$, and the balanced tip remained $<36^{\circ} \mathrm{C}$ in all test conditions. For the mini-flared and balanced tips, temperature increases during operation were not markedly different from free flow and no-load conditions when occlusion or frictional events were simulated.

Conclusion: In all experiments for each tip design, increasing ultrasound power was associated with greater increases in tip temperature. Tip temperatures increased with applied load, but marked temperature increases during occlusion were observed only with the bent-mini tip. The balanced tip produced minimal thermal peaks in all tests.

Keywords: aspiration bypass, balanced tip, cataract, occlusion, temperature, thermal imaging

\section{Introduction}

Ultrasound phacoemulsification (phaco) is the preferred surgical intervention for cataract removal because of its historically successful outcomes with relatively low incidence of complications. ${ }^{1-3}$ Potential complications of phaco, such as incomplete wound closure, corneal scarring, and iatrogenic astigmatism, are in some instances associated with thermal wound damage. ${ }^{4}$ During operation, vibration of the phaco tip can generate considerable thermal energy. Although using sleeved phaco tips (ie, coaxial phaco) may limit thermal damage to the cornea by preventing direct contact between the cornea and the metal tip, ${ }^{5}$ incidental friction between the vibrating tip and its sleeve may contribute significantly to phaco tip heating. ${ }^{6}$ 
The incidence of wound burns was estimated by Bradley and Olson ${ }^{7}$ to be approximately one per 1,000, with most thermal events observed during lens fragment removal and tip occlusion. Mild burns and resultant complications (eg, aqueous humor leakage, induced astigmatism, and corneal inflammation) often resolve over time with appropriate treatment, but moderate-to-severe thermal wound damage can cause visual impairment and may necessitate a second surgery. ${ }^{4,8}$ One study of human cadaver eyes suggested that temperatures upward of $50^{\circ} \mathrm{C}$ can cause corneal burns $;^{9}$ however, thermal damage may occur at lower temperatures as well. ${ }^{9-11}$ Based on these studies, $50^{\circ} \mathrm{C}$ may be considered a reasonable threshold for potential wound burn.

Previous characterizations using human cadaver and postmortem porcine eyes demonstrated that larger temperature increases may occur when phaco tips are operated in longitudinal (ie, axial) versus torsional mode. ${ }^{6,11}$ The forward and back motion of longitudinal phaco may contribute to greater friction-generated thermal energy and decreased surgical efficiency compared with the rotary oscillations of torsional phaco. ${ }^{12}$ Further, thermal peaks are markedly higher during tip occlusion compared with normal operating conditions when aspiration and irrigation fluid flow freely. 5,6,13,14 Thermal energy is typically dissipated by the flow of cooling irrigation and aspiration fluid. If the fluid flow is decreased or interrupted, as occurs during tip occlusion, thermal energy can be dissipated to the tissue, resulting in thermal wound damage. ${ }^{4,7}$ One approach to decreasing occlusion-related tissue damage is the use of a phaco tip with an aspiration bypass port. These tips contain a secondary hole in the tip that maintains fluid flow in the event of tip occlusion. The aspiration bypass tip design may limit temperature increases during phaco procedures, ultimately decreasing the potential for thermal wound damage.

The aim of this study was to define the thermal profiles, using high rate infrared imaging, of three substantially different torsional ultrasound-compatible phaco tip designs with or without an aspiration bypass design operated using torsional ultrasound during free fluid flow and simulated occlusion conditions. Tips were tested at a range of power levels with no-load and $30 \mathrm{~g}$ load applied approximately where an estimated or probable incision location would be to simulate friction at the incision site.

\section{Materials and methods}

\section{Study design}

This was a laboratory investigation conducted at the Pasteur Ophthalmic Clinic in Santiago, Chile. Thermal profiles of three sleeved phaco tips were compared across conditions of varied flow, applied load, and ultrasound power level (ie, amplitude).

\section{Phaco equipment}

Three different sleeved, torsional ultrasound-compatible phaco tips were evaluated: $45^{\circ} 0.9 \mathrm{~mm}$ mini-flared $\mathrm{Kelman}^{\circledR}$ aspiration bypass system tip ("mini-flared tip"; Alcon Laboratories, Inc., Fort Worth, TX, USA); MST $0.9 \mathrm{~mm}$ A1 bent mini phaco tip ("bent-mini tip"; MicroSurgical Technology, Inc., Redmond, WA, USA); and $0.9 \mathrm{~mm}$ Intrepid $^{\circledR}$ balanced aspiration bypass system tip ("balanced tip"; Alcon Laboratories, Inc.; Figure 1A-C; Table 1). The bent-mini tip design is not available with an aspiration bypass port. All tips were tested with the ultra sleeve (Alcon Laboratories, Inc.) and were operated with the Infiniti ${ }^{\circledR} \mathrm{OZil}^{\circledR}$ handpiece (Alcon Laboratories, Inc.) on the Infiniti ${ }^{\circledR}$ Vision System console (Alcon Laboratories, Inc.), which reported operating parameter data in real time. Data capture software simultaneously recorded time, load applied, temperature readings, and console settings. In each test condition, tips were activated at power levels of $50 \%$, $75 \%$, and $100 \%$ amplitude.

\section{Test setup}

The primary test setup for controlling the aspiration flow, ultrasonic phaco energy, and loading of force on the sleeved tips during their operation using blackbody film has been described previously. ${ }^{12}$
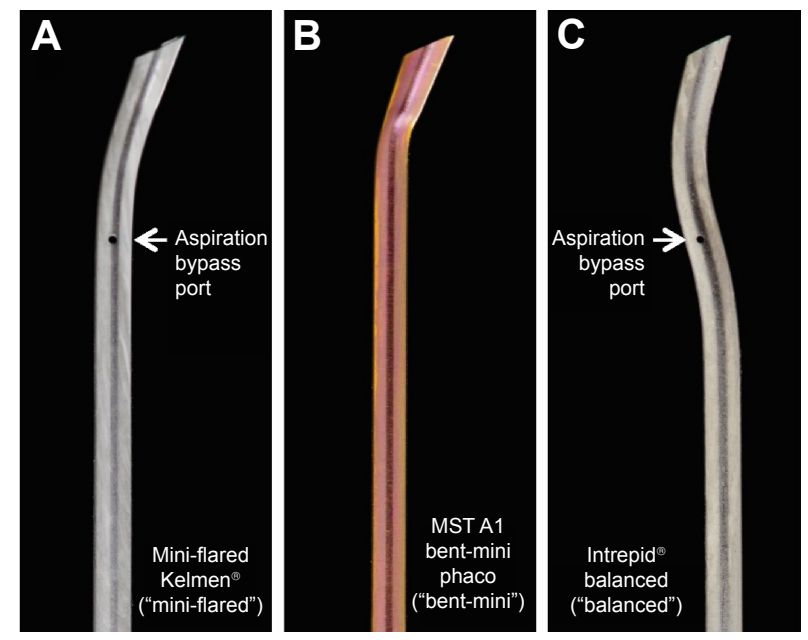

Figure I Phaco tips tested.

Notes: (A) $0.9 \mathrm{~mm}$ mini-flared Kelman ${ }^{\circledR}$ ("mini-flared") tip with aspiration bypass port; (B) MST $0.9 \mathrm{~mm} \mathrm{Al} \mathrm{bent} \mathrm{-mini} \mathrm{phaco} \mathrm{("bent-mini”)} \mathrm{tip} \mathrm{with} \mathrm{no} \mathrm{aspiration}$ bypass port; (C) $0.9 \mathrm{~mm}$ Intrepid ${ }^{\circledR}$ balanced ("balanced") tip with aspiration bypass port. The Alcon ultra sleeve was used with all tips (not shown). 
Table I Phacoemulsification tips assessed

\begin{tabular}{llll}
\hline Phacoemulsification tip & Generic name & Aspiration bypass port & Manufacturer \\
\hline $0.9 \mathrm{~mm}$ mini-flared Kelman ${ }^{\circledR}$ & Mini-flared tip & Yes & Alcon Laboratories, Inc., Fort Worth, TX, USA \\
$0.9 \mathrm{~mm}$ MST Al bent-mini phaco & Bent-mini tip & No & MicroSurgical Technology, Inc., Redmond, WA, USA \\
$0.9 \mathrm{~mm}$ Intrepid ${ }^{\circledR}$ balanced & Balanced tip & Yes & Alcon Laboratories, Inc. \\
\hline
\end{tabular}

A funnel-shaped, water-tight, closed-circuit silicone fluid collection array, fashioned from a cut irrigation sleeve of slightly larger diameter, was attached to the distal end of the coaxial sleeve to maintain circulation in operational conditions and prevent potential splash or spray of irrigation fluid that would compromise the accuracy of temperature measurements (Figure 2). The array was located downstream of the simulated incision region where load was applied and temperatures were measured. For all experiments, distilled water was used as irrigation fluid instead of saline solution to keep sensitive equipment protected from salt residue. The temperature of the irrigation fluid was controlled by passing the irrigation tubing through a chilled bath to maintain a set temperature of $26^{\circ} \mathrm{C} \pm 2{ }^{\circ} \mathrm{C}$. A flow rate of $20 \mathrm{~mL} / \mathrm{min}$ was used for all experiments.

To simulate mechanical manipulation of the phaco tip at a corneal incision site and the resultant sleeve/tip compression against the incision wall, an automated cyclic loading system driven by a computer-controlled linear actuator was used to apply an intermittent repeatable load of $30 \mathrm{~g}$, as previously described. ${ }^{12}$ This load, representing the pressure of the incision wall against the sleeved phaco tip, was applied by pulling a $2 \mathrm{~mm}$ wide strip of blackbody film (plastic-based carbon paper; Kores, Vienna, Austria) against the shaft portion of the sleeved phaco tip (Figure 2), between 4 and $8 \mathrm{~mm}$ proximal to the tip end, which was estimated to correspond with the typical site of contact with the incision

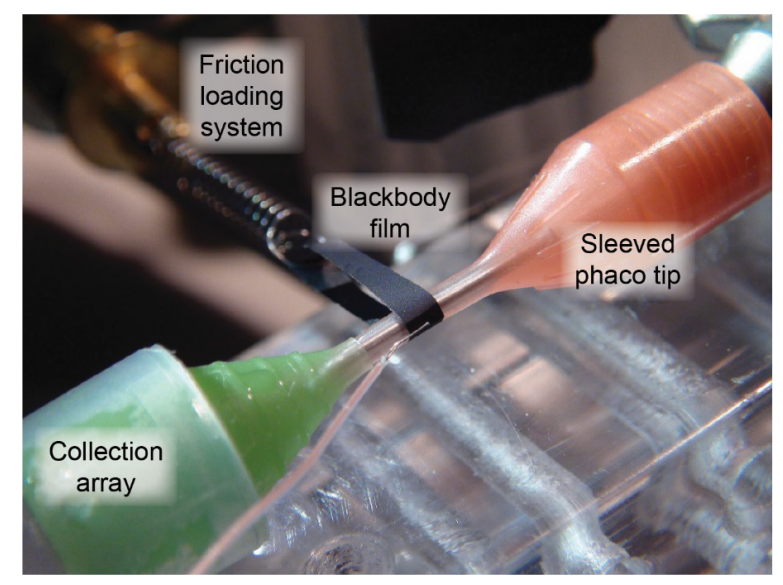

Figure 2 Test setup.

Note: Closed-circuit fluid collection array setup with automated loading system. tunnel. The blackbody film was used to transmit variable loads to the tip-sleeve complex to enable modification of friction between the silicone sleeve and the titanium phaco tip. The blackbody film also enabled accurate measurement of the temperature of the tip-sleeve complex at its point of contact between the sleeve and the simulated incision, as previously demonstrated. ${ }^{12}$ When applying the intermittent load with the blackbody film upon the sleeved phaco tip, the tip temperature would rise due to friction. As a near-perfect thermal emitter, the thin blackbody film relayed thermal responses of the tip-sleeve complex without significantly influencing temperature readings.

Data recordings were collected after steady state was achieved ( 10 seconds after ultrasonic activation of a given tip was initiated). Infrared thermal imaging with a FLIR SC-305 camera (accuracy, $\pm 2^{\circ} \mathrm{C}$; FLIR Systems, Inc., Wilsonville, OR, USA) was used to capture 16-bit images of the tip surface temperature at a rate of nine frames per second. Analysis of infrared imaging data was performed using the FLIR Systems' ExaminIR software (FLIR Systems, Boston, MA, USA).

\section{Simulation of full- and reduced-flow occlusions}

Occlusion was simulated by clamping the aspiration line at the back of the handpiece. By creating an occlusion in this manner instead of directly at the opening of the aspirating tip, as would normally occur during surgery, the limited flow maintained by an aspiration bypass port would be prevented. Therefore, to enable continued flow through the aspiration bypass hole using this simulated occlusion arrangement, a separate aspiration line was installed in parallel with the primary aspirating fluidic tubing (Figure 3). This secondary "bypass" tubing held within it an aspiration bypass port-equipped tip that was modified to prevent fluid through its main throat and allow flow only through the aspiration bypass hole. Clamping the main fluidic tubing downstream of these parallel aspiration paths produced complete flow occlusion, while clamping the tubing only on the main aspiration line allowed flow through an opening identical to the size of the aspiration bypass port and therefore allowed the expected amount of fluid to flow by simulating an aspiration bypass system-equipped tip (ie, minimal flow, but not full occlusion). 


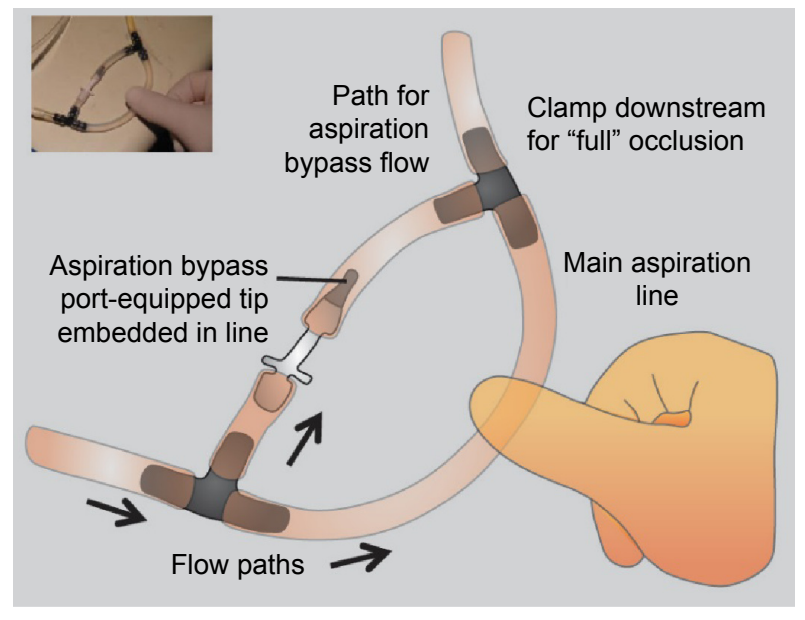

Figure 3 Setup with secondary bypass tubing to enable minimal flow through aspiration bypass-equipped phaco tips during simulated occlusion.

Note: Inset depicts photograph of setup.

\section{Data analysis}

For each tip design, four test replicates of a single tip were performed for each test condition. Data were summarized using descriptive statistics (mean \pm standard deviation).

\section{Results}

Baseline tip temperature was $25.9^{\circ} \mathrm{C} \pm 0.4^{\circ} \mathrm{C}$ (mean \pm standard deviation) for all tips and test conditions. When operated in conditions of free flow (ie, $20 \mathrm{~mL} / \mathrm{min}$ ) with no load applied, tip temperature increased with increasing ultrasound amplitude. At all power levels tested (ie, 50\%, $75 \%$, and $100 \%$ amplitude), the mini-flared tip demonstrated the largest temperature increase, while the balanced tip demonstrated the smallest temperature increase (Figure 4A). At $100 \%$ amplitude, tip temperature increased from baseline by $21.8^{\circ} \mathrm{C}$ for the mini-flared tip, $11.3^{\circ} \mathrm{C}$ for the bent-mini tip, and $3.4^{\circ} \mathrm{C}$ for the balanced tip. Absolute temperatures remained $<30^{\circ} \mathrm{C}$ with the balanced tip and $<40^{\circ} \mathrm{C}$ with the bent-mini tip. The mini-flared tip reached an absolute temperature of $\sim 48^{\circ} \mathrm{C}$.

When tip occlusion was simulated with no load applied to tips, temperature increases of the mini-flared and balanced tips were slightly higher at steady state conditions compared with conditions of free flow. For the mini-flared and the balanced tip, the temperature increase from baseline during simulated occlusion ranged from $12.6^{\circ} \mathrm{C}$ and $2.3^{\circ} \mathrm{C}$ at $50 \%$ amplitude to $24.5^{\circ} \mathrm{C}$ and $6.4^{\circ} \mathrm{C}$ at $100 \%$ amplitude (Figure 4B), respectively. Differences in temperature increase between free flow and occluded conditions were unremarkable for the mini-flared and balanced tips at all amplitudes tested $\left(<3.0^{\circ} \mathrm{C}\right.$ for both). With no load applied to tips, temperature increases were considerably higher for the bent-mini tip when occlusion was simulated compared with conditions of free flow. Temperature increases from baseline during occlusion were largest with the bent-mini tip, which reached absolute temperatures of $\sim 45^{\circ} \mathrm{C}$ at $50 \%$ amplitude and $53^{\circ} \mathrm{C}$ at $100 \%$ amplitude.

When load was applied to tips during conditions of free flow, the mini-flared and balanced tips demonstrated temperature increases comparable to those observed with no load. At $50 \%$ amplitude, tip temperature increased from baseline by $13.7^{\circ} \mathrm{C}$ for the mini-flared tip and by $3.4^{\circ} \mathrm{C}$ for the balanced tip (Figure 5A). At 100\% amplitude, temperature increases from baseline were $23.6^{\circ} \mathrm{C}$ and $6.3^{\circ} \mathrm{C}$, respectively. Temperature increases for the bent-mini tip were considerably larger when load was applied compared with no-load conditions; tip temperature increased from baseline by $16.4^{\circ} \mathrm{C}$ at $50 \%$ amplitude, by $25.0^{\circ} \mathrm{C}$ at $75 \%$ amplitude, and by $29.7^{\circ} \mathrm{C}$ at $100 \%$ amplitude. At each ultrasound power level tested with no load, the bent-mini tip demonstrated the highest absolute
A

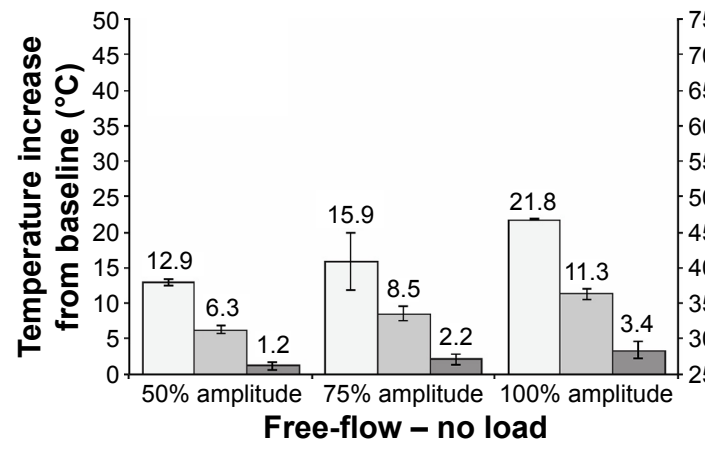

B

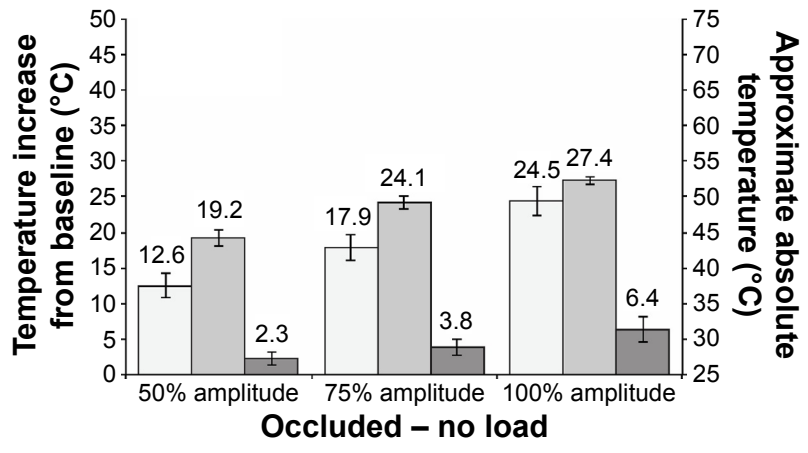

$\square$ Mini-flared tip $\square$ Bent-mini tip $\square$ Balanced tip

Figure 4 Tip temperature increase from baseline with no load and increasing power (amplitude).

Notes: Tips were tested $(\mathbf{A})$ in free-flow conditions and $(\mathbf{B})$ during simulated occlusion. Mean temperature increase is indicated above bars; $\mathrm{n}=4$ replicates per test condition. 
A

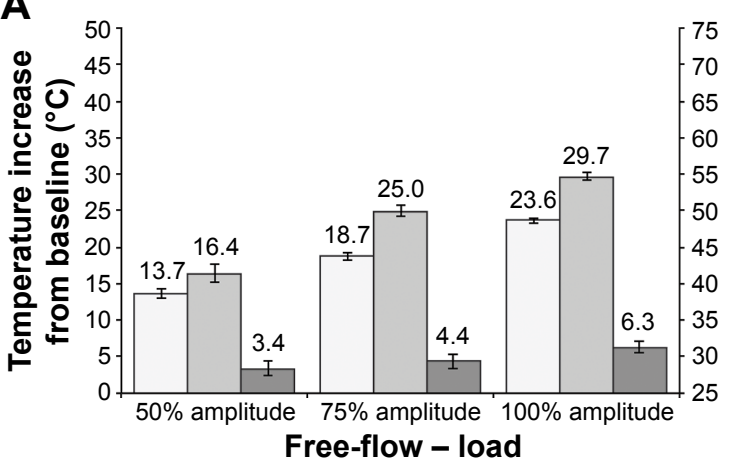

B

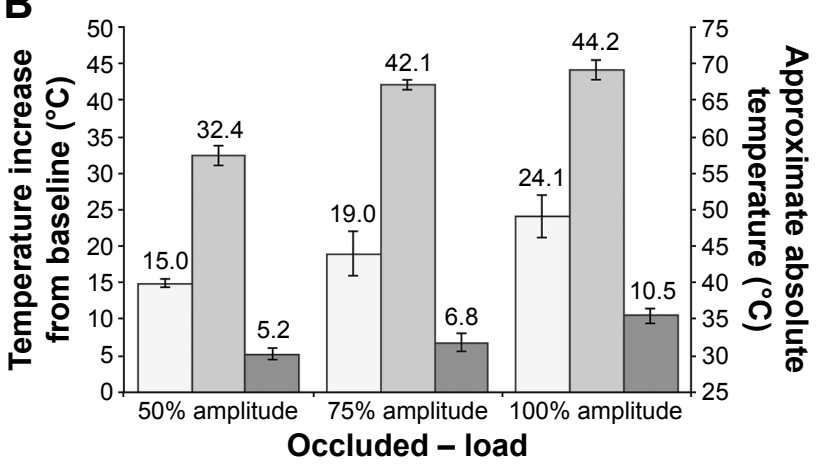

$\square$ Mini-flared tip $\square$ Bent-mini tip $\square$ Balanced tip

Figure 5 Tip temperature increase from baseline with a $30 \mathrm{~g}$ applied load and increasing power (amplitude).

Notes: Tips were tested $(\mathbf{A})$ in free-flow conditions and $(\mathbf{B})$ during simulated occlusion. Mean temperature increase is indicated above bars; $\mathrm{n}=4$ replicates per test condition.

temperature of the three tips tested, reaching $\sim 55^{\circ} \mathrm{C}$ at $100 \%$ amplitude during conditions of free flow.

When occlusion was simulated with load applied to tips, temperature increases for the mini-flared and balanced tips were similar to conditions of free flow with load (Figure 5B). The balanced tip remained below $\sim 35^{\circ} \mathrm{C}$ at all power levels, and the mini-flared tip remained below $\sim 50^{\circ} \mathrm{C}$. Temperature increases from baseline for the bent-mini tip were markedly larger and ranged from $32.4^{\circ} \mathrm{C}$ at $50 \%$ amplitude to $44.2^{\circ} \mathrm{C}$ at $100 \%$ amplitude. The absolute temperature of the bentmini tip at $50 \%$ and $100 \%$ amplitudes reached $\sim 57^{\circ} \mathrm{C}$ and $70^{\circ} \mathrm{C}$, respectively.

\section{Discussion}

Ultrasound phaco surgery for cataract removal has a low rate of complications; however, when complications occur, vision may be compromised. ${ }^{8}$ Thermal energy transfer to corneal incision sites during ultrasound phaco cataract removal can cause corneal burns that may potentially impair wound healing or lead to postoperative astigmatism., ${ }^{4,15}$ Ultrasound activation of phaco tips generates significant heat owing to friction between the tip and the sleeve, which increases with compression caused by tip manipulation within clear corneal incisions. ${ }^{6}$ The goal of this study was to evaluate the thermal profiles of three phaco tips of different designs under simulated surgical conditions; evaluating tips with substantially different designs enabled elucidation of the potential role of different design elements (eg, presence versus absence of an aspiration bypass hole). Overall, the balanced tip maintained the lowest absolute temperatures and demonstrated the most consistent temperature increases from baseline across power levels and test conditions. Temperature increases observed for the mini-flared tip were also generally consistent under conditions of load and occlusion. The bent-mini tip demonstrated markedly greater temperature increases from baseline during simulated occlusion compared with conditions of free flow when no load was applied.

Under conditions of free fluid flow with no load applied, tip temperatures generally remained $<42^{\circ} \mathrm{C}$. Under the most extreme test conditions ( $100 \%$ power with simulated occlusion and load applied), temperature of the bent-mini tip reached $\sim 70^{\circ} \mathrm{C}$, whereas the mini-flared tip reached $\sim 50^{\circ} \mathrm{C}$, and the balanced tip reached a maximum mean temperature of $36^{\circ} \mathrm{C}$. The temperature of the balanced tip remained well below the estimated $50^{\circ} \mathrm{C}$ threshold for potential thermal damage. The temperatures reached by the bent-mini tip during occlusion with load $\left(\sim 58^{\circ} \mathrm{C}-70^{\circ} \mathrm{C}\right)$ were similar to those associated with corneal burns in postmortem porcine eyes subjected to coaxial phaco with sleeved Kelman tips without aspiration bypass ports $\left(63^{\circ} \mathrm{C}-71^{\circ} \mathrm{C}\right) .^{5}$ In previous studies of postmortem porcine and human cadaver eyes, temperatures as low as $43^{\circ} \mathrm{C}-50^{\circ} \mathrm{C}$ were sufficient to cause corneal burns. ${ }^{9-11}$ The lower temperatures observed with the mini-flared and balanced tips were attributed to the presence of an aspiration bypass hole in these tips; the bent-mini tip lacks a bypass hole and therefore cannot maintain cooling fluid flow during occlusion events. Under all test conditions and ultrasound power settings, the balanced aspiration bypass port-equipped tip remained well below the temperature threshold for corneal damage; the highest temperature observed with this tip was $\sim 36^{\circ} \mathrm{C}\left(\sim 11^{\circ} \mathrm{C}\right.$ increase from baseline) and this occurred during simulated occlusion with load applied.

The finding that temperature increases from baseline were greater when load was applied to the tips and during simulated occlusion is consistent with previous studies that 
identified friction between the sleeve and phaco tip, and occlusion events as sources of thermal energy. ${ }^{5,11}$ In the current study, larger temperature increases were observed with the added thermal output created by application of the $30 \mathrm{~g}$ load, combined with the complete lack of cooling fluid flow for the bent-mini tip during occlusion. Presence of an aspiration bypass port mitigated these frictional effects for the mini-flared and balanced tips by maintaining partial fluid flow; temperatures of these tips were generally maintained below those implicated in corneal thermal damage.

Tip design has been identified as a factor in observed variations in temperature increases during phaco surgery. ${ }^{10}$ As discussed earlier, maintenance of continuous cooling fluid flow by the aspiration bypass port in the mini-flared and balanced tips was likely the key factor in the limited temperature increases observed during simulated occlusion of these tips. The balanced tip, which maintained the lowest temperatures in all test conditions, demonstrated minimal temperature increases during occlusion regardless of whether load was applied. The consistently lower temperatures observed during free-flow conditions with the balanced tip may be related to the design of the tip, which is intended to function similarly to a straight tip during torsional phaco, resulting in an improved thermal profile during operation. Specifically, the balanced tip is designed to vibrate less at the shaft, which would be in contact with the incision site during surgery, and more at the distal end, which would be within the anterior chamber in contact with the lens and away from the corneal incision. Because heat is a function of stroke length and frequency, among other factors, the shorter effective stroke length at the simulated incision site with the balanced tip, compared with other tips operated at the same ultrasound frequency using the same handpiece, likely contributed to the lower temperatures that were produced.

This study was designed to assess the thermal output of different tip designs under a variety of operating conditions (ie, varied flow, load, and ultrasound power). Additional studies investigating the contribution of phaco tip design on tip movement and tip-to-sleeve friction, as well as the individual contribution of these variables to overall thermal output, are needed. Furthermore, the extreme, multifactorial test conditions associated with the highest absolute temperatures in this study (ie, full occlusion and simultaneous application of a $30 \mathrm{~g}$ load during ultrasound activation at 100\% amplitude) were used for bench testing purposes and are unlikely to occur in the clinical setting. During cataract phaco, operational conditions (eg, ultrasound power) are adjusted to compensate for events (eg, tip occlusion) that could lead to increased tip temperatures and potential wound burn. Therefore, even if a combination of the conditions simulated in the current study were to occur during surgery, absolute tip temperatures would likely be lower than the maximum temperatures reported here. The current study did not evaluate rates of temperature change during tip operation. Future studies assessing phaco tip temperatures in conditions more closely simulating typical cataract surgery will add valuable context to the results of the current study.

\section{Conclusion}

Friction between the tip and sleeve generated considerable thermal energy, particularly when load was applied to phaco tips. Lack of aspiration/irrigation fluid during simulated occlusion led to temperature increases of the bent-mini tip, particularly when load was applied, while fluid flow maintained by the aspiration bypass port in the mini-flared and balanced tips limited temperature increases. The balanced tip produced less heat than the other tips, demonstrating the smallest temperature increase $\left(<11^{\circ} \mathrm{C}\right)$ in even the most extreme test conditions and maintaining absolute temperatures $<36^{\circ} \mathrm{C}$ at all ultrasound amplitudes and test conditions.

\section{Acknowledgments}

This study was sponsored by Alcon Laboratories, Inc. (Fort Worth, TX, USA). The author thanks Ramon Dimalanta, $\mathrm{PhD}$, of Alcon Research, Ltd (Irvine, CA, USA), who aided in the completion of this study. Scientific writing assistance was provided by Heather D Starkey, PhD, of Complete Healthcare Communications, Inc. (Chadds Ford, PA, USA) and was funded by Alcon Laboratories, Inc. Alcon participated in revising the manuscript and supported the decision to submit the manuscript for publication.

\section{Disclosure}

The author has no financial or proprietary interests in the devices described and reports no conflicts of interest in this work.

\section{References}

1. Gogate PM, Kulkarni SR, Krishnaiah S, et al. Safety and efficacy of phacoemulsification compared with manual small-incision cataract surgery by a randomized controlled clinical trial: six-week results. Ophthalmology. 2005;112(5):869-874.

2. Lundstrom M, Barry P, Henry Y, Rosen P, Stenevi U. Evidence-based guidelines for cataract surgery: guidelines based on data in the European Registry of Quality Outcomes for Cataract and Refractive Surgery database. J Cataract Refract Surg. 2012;38(6):1086-1093.

3. Tsinopoulos IT, Lamprogiannis LP, Tsaousis KT, et al. Surgical outcomes in phacoemulsification after application of a risk stratification system. Clin Ophthalmol. 2013;7:895-899. 
4. Majid MA, Sharma MK, Harding SP. Corneoscleral burn during phacoemulsification surgery. J Cataract Refract Surg. 1998;24(10): 1413-1415.

5. Abulafia A, Michaeli A, Belkin A, Assia EI. Temperature profiles of sleeveless and coaxial phacoemulsification. J Cataract Refract Surg. 2013;39(11):1742-1748.

6. Han YK, Miller KM. Heat production: longitudinal versus torsional phacoemulsification. J Cataract Refract Surg. 2009;35(10): 1799-1805.

7. Bradley MJ, Olson RJ. A survey about phacoemulsification incision thermal contraction incidence and causal relationships. Am J Ophthalmol. 2006;141(1):222-224.

8. Khodabakhsh AJ, Zaidman G, Tabin G. Corneal surgery for severe phacoemulsification burns. Ophthalmology. 2004;111(2):332-334.

9. Olson MD, Miller KM. In-air thermal imaging comparison of Legacy AdvanTec, Millennium, and Sovereign WhiteStar phacoemulsification systems. J Cataract Refract Surg. 2005;31(8):1640-1647.

10. Bissen-Miyajima H, Shimmura S, Tsubota K. Thermal effect on corneal incisions with different phacoemulsification ultrasonic tips. J Cataract Refract Surg. 1999;25(1):60-64.
11. Jun B, Berdahl JP, Kim T. Thermal study of longitudinal and torsional ultrasound phacoemulsification: tracking the temperature of the corneal surface, incision, and handpiece. J Cataract Refract Surg. 2010;36(5): 832-837.

12. Zacharias J. Thermal characterization of phacoemulsification probes operated in axial and torsional modes. J Cataract Refract Surg. 2015; 41(1):208-216.

13. Ernest P, Rhem M, McDermott M, Lavery K, Sensoli A. Phacoemulsification conditions resulting in thermal wound injury. J Cataract Refract Surg. 2001;27(11):1829-1839.

14. Osher RH, Injev VP. Thermal study of bare tips with various system parameters and incision sizes. J Cataract Refract Surg. 2006;32(5): 867-872.

15. Sugar A, Schertzer RM. Clinical course of phacoemulsification wound burns. J Cataract Refract Surg. 1999;25(5):688-692.
Clinical Ophthalmology

\section{Publish your work in this journal}

Clinical Ophthalmology is an international, peer-reviewed journal covering all subspecialties within ophthalmology. Key topics include: Optometry; Visual science; Pharmacology and drug therapy in eye diseases; Basic Sciences; Primary and Secondary eye care; Patien Safety and Quality of Care Improvements. This journal is indexed on

Submit your manuscript here: http://www.dovepress.com/clinical-ophthalmology-journal

\section{Dovepress}

PubMed Central and CAS, and is the official journal of The Society of Clinical Ophthalmology (SCO). The manuscript management system is completely online and includes a very quick and fair peer-review system, which is all easy to use. Visit http://www.dovepress.com/ testimonials.php to read real quotes from published authors. 